\title{
mTOR-dependent upregulation of xCT blocks melanin synthesis and promotes tumorigenesis
}

\author{
Chunjia $\mathrm{Li}^{1,2} \cdot$ Hongyu Chen ${ }^{1} \cdot \mathrm{Zhou} \mathrm{Lan}^{3}$. Shaozong He${ }^{1} \cdot$ Rongrong Chen ${ }^{1} \cdot$ Fang Wang ${ }^{1} \cdot \mathrm{Zhibo} \mathrm{Liu}^{1} \cdot \mathrm{Kai} \mathrm{Li}^{1} \cdot$ \\ Lili Cheng ${ }^{3} \cdot \mathrm{Ye} \mathrm{Liu}^{3} \cdot \mathrm{Kun} \mathrm{Sun}^{3} \cdot \mathrm{Xiaofeng} \mathrm{Wan}^{4} \cdot$ Xinxin Chen ${ }^{1} \cdot$ Haiyong Peng ${ }^{1} \cdot \mathrm{Li} \mathrm{Li}^{1} \cdot$ Yanjun Zhang ${ }^{1}$. \\ Yanling Jing ${ }^{1} \cdot$ Min Huang ${ }^{5} \cdot$ Yanan Wang ${ }^{1} \cdot$ Yan Wang $^{5} \cdot$ Jiandong Jiang $^{5} \cdot$ Xiaojun Zha $^{4} \cdot$ Ligong Chen $^{3}$. \\ Hongbing Zhang ${ }^{1,6}$
}

Received: 24 July 2016 / Revised: 14 December 2018 / Accepted: 20 December 2018 / Published online: 13 February 2019

(c) ADMC Associazione Differenziamento e Morte Cellulare 2019

\begin{abstract}
Loss of either TSC1 or TSC2 causes tuberous sclerosis complex (TSC) via activation of mTOR signaling pathway. The two prominent features of TSC are skin lesions including hypomelanic macules and benign tumors in multiple organs, whose molecular alterations are largely unknown. We report here that $\mathrm{X}_{\mathrm{c}}^{-}$cystine/glutamate antiporter $(\mathrm{xCT})$ was elevated in $T_{s c 2^{-/-}}$or $\mathrm{Pten}^{-/-}$cells, Tscl knockout mouse tissues and TSC2-deficient human kidney tumor. xCT was transcriptionally boosted by mTOR-mediated Oct1 signaling cascade. Augmented xCT led to reduction of eumelanin and elevation of pheomelanin in $T s c 1$ skin knockout mice through mTOR signaling pathway. Disruption of $\mathrm{xCT}$ suppressed the proliferation and tumorigenesis of Pten-null cells and Tsc2-null cells. mTOR hyperactive cells were more sensitive to inhibitors of mTOR or xCT. Combined inhibition of mTOR and xCT synergistically blocked the propagation and oncogenesis of mTOR hyperactive cells. Therefore, oncogenic mTOR activation of $\mathrm{xCT}$ is a key connection between aberrant melanin synthesis and tumorigenesis. We suggest that $\mathrm{xCT}$ is a novel therapeutic target for TSC and other aberrant mTOR-related diseases.
\end{abstract}

\section{Introduction}

Mammalian/mechanistic target of rapamycin (mTOR) is a serine/threonine protein kinase [1,2]. Through the upstream

These authors contributed equally: Chunjia Li, Hongyu Chen

Edited by V. Stambolic

Supplementary information The online version of this article (https:// doi.org/10.1038/s41418-019-0274-0) contains supplementary material, which is available to authorized users.

Ligong Chen

ligongchen@tsinghua.edu.cn

$\triangle$ Hongbing Zhang

hbzhang@ibms.pumc.edu.cn

1 State Key Laboratory of Medical Molecular Biology, Department of Physiology, Institute of Basic Medical Sciences \& School of Basic Medicine, Graduate School of Peking Union Medical College, Chinese Academy of Medical Sciences, Beijing 100005, China

2 Department of Blood Transfusion, China-Japan Friendship Hospital, Beijing 100029, China membrane receptor tyrosine kinase (RTK)-PI3K/PTENAKT-TSC1/2 signaling pathway, mTOR integrates nutrients, growth factors and energy signalings to regulate various life processes, including protein synthesis, autophagy, and metabolism [3-8]. Its physiological function is thereby critical for cell growth, proliferation, differentiation, and survival. Gain of function mutations in proto-oncogenes such as $R T K s, P 13 K$, or $A K T$, and loss of function mutations in tumor suppressor genes such as PTEN and TSC1/ TSC2 in the upstream of the mTOR pathway render this signaling pathway as one of the most frequently

3 School of Pharmaceutical Sciences, Tsinghua University, Beijing 100084, China

4 Department of Biochemistry \& Molecular Biology, School of Basic Medicine, Anhui Medical University, Hefei 230032 Anhui, China

5 State Key Laboratory of Bioactive Substance and Function of Natural Medicines, Institute of Materia Medica, Chinese Academy of Medical Sciences and Peking Union Medical College, Beijing 100050, China

6 Department of Neurology, Institute of Neural Regeneration and Repair, The First Hospital of Yichang, College of Medicine, Three Gorges University, Yichang 443000, China 
dysregulated signaling cascades in human diseases, especially in cancers [9-15].

Hyperactive mTOR signaling due to loss of functional mutations in either TSC1 or TSC2 gene causes tuberous sclerosis complex (TSC) [16, 17]. TSC is an autosomal dominant genetic disorder associated with benign tumors in multiple organs such as heart, brain, and kidneys [18-24]. As the foremost visible sign since birth in TSC patients, hypopigmented macules can be found in more than $95 \%$ TSC patients [25-31]. However, the mechanisms how hypopigmented macules developed and tumor formed are not well elucidated. Skin biopsy of the hypopigmented macules from TSC patients suggests, compared with surrounding normal skin, there is no difference in the number of melanocytes [32, 33]. Therefore, we speculated that the abnormal pigment metabolism might be the underlying pathological mechanism. In mammals, pigment melanin can be classified into two major groups: the brown-to-black eumelanin and the yellow-to-reddish-brown pheomelanin [34]. The color of hair, skin, and eyes in animals mainly depends on the quantity, quality, and distribution of the pigment melanin [35]. Slc7all gene encodes the plasma membrane exchanger xCT [36]. The xCT transporter brings cystine into cells $[37,38]$. Once inside a cell, cystine is rapidly reduced to cysteine, which can enter pheomelanin, glutathione, and protein biosynthetic pathways [38, 39], and promote production of pheomelanin pigment [36], as well as for the growth and survival of cancers [40, 41]. Therefore, $\mathrm{xCT}$ acts in a permissive role in formation of hypopigmented macules and tumor growth.

To explore the potential role of mTOR hyperactivation in melanogenesis, we analyzed the status of melanin synthesis in $\mathrm{TsCl}^{-/-}$mouse skin. We then checked the expression of $\mathrm{xCT}$ in mTOR-activated cells and tissues due to TSC2 or PTEN deficiency. Moreover, we elucidated the mechanism of mTOR regulation of $\mathrm{xCT}$ expression. Lastly, we tested the significance of $\mathrm{xCT}$ in formation of hypopigmented macules and oncogenic mTOR-mediated tumor development.

\section{Materials and methods}

\section{Antibodies and reagents}

The antibodies against phosphor-S6 S235/236 (rabbit, 2211s, 1:1000), phosphor-S6 S240/244 (rabbit, 5364, 1:1000), S6 (rabbit, 2217s, 1:1000), PTEN (rabbit, 9559s, 1:1000), phosphor-S6K $^{\mathrm{T} 389}$ (rabbit, 9234, 1:1000), S6K1 (rabbit, 2708, 1:1000), phosphor-AKT ${ }^{\text {S473 }}$ (rabbit, 4060, 1:1000), AKT1 (rabbit, 4691, 1:1000), Raptor (rabbit, 2280s, 1:1000), and Rictor (rabbit, 2140s, 1:1000) were from Cell Signaling Technology (Danvers, MA, USA). Rabbit xCT antibody
(NB300-318, 1:1000) was from Novus Biologicals (Littleton, CO, USA). Oct1 (rabbit, Ab15112) antibody for Western blot (1:1000) and ChIP (1:50) was from Abcam (Cambridge, MA, USA). Rabbit IgG (sc-2027, 1:50), all of HRP-labeled secondary antibodies (1:4000), TSC2 (rabbit, sc-893, 1:1000), and $\beta$-actin (mouse, sc-47778, 1:2000) antibodies were from Santa Cruz Biotechnology (Santa Cruz, CA, USA). Rapamycin was obtained from North China Pharmaceutical Group Corporation (Shijiazhuang, Hebei, China). Fetal bovine serum, Dulbecco's modified Eagle's medium (DMEM), Lipofectamine 2000, and 4-12\% Bis-Tris NuPAGE gels were from Invitrogen (Carlsbad, CA, USA). XhoI, HpaI, NotI, and ClaI were from Takara (Shiga, Japan). Reactive Oxygen Species Assay Kit (S0033) and N-acetyl-L-cysteine (NAC) (S0077) were from Beyotime Institute of Biotechnology (Shanghai, China). Sulfasalazine (SASP) (S0883) and ferrostatin-1 (Ferr1) (SML0583) was from Sigma-Aldrich (St. Louise, MO, USA). Z-VAD-FMK (S7023) and necrostatin-1 (Nec-1) (S8037) were from Selleck (Houston, TX, USA).

\section{Synthesis of pyrrole-2,3,5-tricarboxylic acid (PTCA) and 4-amino-3-hydroxyphenylalanine (4-AHP)}

PTCA and 4-AHP were synthesized as previously reported [42], 1H NMR and 13C NMR spectra were recorded using spectrometers (Bruker, MA, USA) at 300 or $400 \mathrm{MHz}$ and 75 or $100 \mathrm{MHz}$. Chemical shifts $(\delta)$ of the signals are quoted in ppm, using residual solvent peaks as external standard. All coupling constants $J$ are listed with the numbers of involved bonds in Hertz (Hz) SI. Synthesized PTCA and 4-AHP were evidenced by $1 \mathrm{H}-\mathrm{NMR}$ and 13CNMR, respectively. The PTCA's spectra was shown below: 1H-NMR (300 MHz, DMSO-d6): $\delta 12.209$ (s, 1H,-COOH), $7.069(\mathrm{~d}, 4 \mathrm{~J}=2.7 \mathrm{~Hz}, 1 \mathrm{H}$, arom H). 13C-NMR $(75 \mathrm{MHz}$,

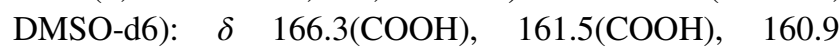
$(\mathrm{COOH}), 130.5(\operatorname{arom~C}), 124.7$ (arom C), 119.6(arom C), and 117.7(arom C). The 4-AHP's spectra was shown below: 1H-NMR (400 MHz, D2O): $\delta 7.17-7.15(\mathrm{~m}, 1 \mathrm{H}$, arom H), 6.79-6.72(m, 2H, arom H). 13C-NMR (100 MHz, D2O): $\delta$ 171.9(COOH), 151.1 (arom C), 137.4(arom C), 125.4(arom C), 122.1(arom C), 118.0(arom C), 117.9(arom C), 54.6 $(\mathrm{CH}), 35.9(\mathrm{CH} 2)$.

\section{Cell culture}

Rat uterine leiomyoma-derived Tsc2-null ELT3 cells, WT, $\mathrm{Tsc}^{-/-}$and $\mathrm{Pten}^{-/-}$mouse embryonic fibroblasts (MEF) have been described previously [11, 43, 44]. MDA-MB-468 cell line was from American Type Culture Collection (Manassas, VA, USA). All of these cells were cultured in DMEM, supplemented with $10 \%$ fetal bovine serum and $1 \%$ penicillin/streptomycin, and maintained in $5 \% \mathrm{CO}_{2}$ at $37^{\circ} \mathrm{C}$. 


\section{Immunoblotting}

Whole cells were lysed in buffer containing $10 \%$ glycerol, 2\% SDS, $10 \mathrm{mM}$ Tris (pH 6.8), and $100 \mathrm{mM}$ dithiothreitol, boiled for $10 \mathrm{~min}$, and then used for immunoblotting [7].

\section{Cell proliferation and viability analysis}

A total of $2 \times 10^{4}$ ELT3 or Pten $^{-/}$cells with sh $v$ or $\operatorname{sh} x C T$ were seeded in 12-well plates and the cell numbers were then counted at day $1-3$, respectively. Totally, $2 \times 10^{4} \mathrm{WT}$ or $T s c 2^{-/-}$MEFs were seeded in 12-well plates and treated with $10 \mathrm{nM}$ rapamycin and/or $0.15 \mathrm{mM}$ SASP for $48 \mathrm{~h}$. A total of $2 \times 10^{4} T s c 2^{-1-}$ MEFs were seeded in 12 well plates and treated with SASP in combination with NAC, Ferr-1, Z-VAD-FMK, or Nec-1 for $48 \mathrm{~h}$. Cell proliferation and viability were determined by Beckman Coulter Vi-Cell XR (Brea, CA, USA) using Trypan blue exclusion staining.

\section{siRNA knockdown for mouse Raptor and Rictor}

Small interfering RNA oligonucleotides for Raptor, Rictor, and negative control were synthesized by Shanghai GenePharma Company. Cells were seeded in 6-well plates and transfected with siRNA using Lipofectamine 2000 for $48 \mathrm{~h}$ following the manufacturer's instructions. The target sequences are listed below.

mouse Raptor: 5'-AAGGACAACGGTCACAAGTAC-3' mouse Rictor: 5'-AAGCCCTACAGCCTTCATTTA-3' Negative control: 5'-TTCTCCGAACGTGTCACGT-3'

\section{xCT knockdown in $\mathrm{TsC2}^{-/-}$and Pten $^{-/-}$MEFs}

shRNA was designed to target mouse $\mathrm{xCT}$. The forward and reverse primers were annealed and cloned into pLL3.7 vector through XhoI and HpaI sites. Viruses were collected after $48 \mathrm{~h}$ and then filtered through a $0.45 \mathrm{~mm}$ filter for cell infection. The target sequence is 5'-GGGCATACTCCAGAACACG-3'.

\section{Oct1 knockdown in $\mathrm{TsC2}^{-/-}$MEFs}

pGPU6/Hygro shRNA expression vector was inserted with mouse Oct1 target sequences through BamHI and BbsI. The target sequence of mouse Oct1 is 5'-GCACAGGCACACAAACCAATG- $3^{\prime}$. An empty control vector and the vector with Oct1 were transfected into $T s c 2^{-/-}$MEFs using Lipofectamine 2000 following the manufacturer's instruction. After $48 \mathrm{~h}$, cell lysates were harvested for immunoblotting.
TSC2 ectopic expression in Tsc2-deficient ELT3 cells

Retroviruses were generated as reported previously [45]. Viruses were collected after $48 \mathrm{~h}$ and then filtered through a $0.45 \mathrm{~mm}$ filter for transduction of ELT3 Cells. The infected cells were selected with $100 \mu \mathrm{g} / \mathrm{mL}$ hygromycin.

\section{Reactive oxygen species (ROS) analysis by flow cytometry}

Cells were stained with $2^{\prime}, 7^{\prime}$-dichlorodihydrofluorescein diacetate (DCFH-DA) according to the manufacturer's instructions. Briefly, $8 \times 10^{4} T s c 2^{-/-}$MEF cells were incubated with $0.15 \mathrm{mM}$ SASP or vehicle for $48 \mathrm{~h}$. The cells were washed twice with PBS, and then incubated with $10 \mu \mathrm{M}$ DCFH-DA for $20 \mathrm{~min}$ at $37^{\circ} \mathrm{C}$. After washing with PBS, cells were harvested and analyzed for the fluorescence of DCFH by flow cytometry (BD Accuri ${ }^{\mathrm{TM}}$ C6, Franklin Lakes, NJ, USA).

\section{Real-time quantitative PCR}

Total RNA was extracted from cells using Trizol (Invitrogen) following the manufacturer's instructions. RNA was reversely transcribed using PrimeScript RT Reagent Kit (Takara) in a total volume of $20-\mu \mathrm{l}$ reaction. After 20 -fold dilution, $4 \mu \mathrm{l}$ of cDNA was used in a $20-\mu \mathrm{l}$ real-time polymerase chain reaction (RT-PCR) reaction. Amplification was run for 40 cycles using TransStart Green quantitative PCR (qPCR) SuperMix (TransGen Biotech, Beijing, China). Oligonucleotide primers were synthesized to detect $\mathrm{xCT}$ with $\beta$-actin as internal control. Exon junctions were used to design primers to prevent coamplification of genomic DNA. The sequences were as follows:

mouse $\beta$-Actin forward: 5'-AGAGGGAAATCGTGCGT GAC-3'

mouse $\beta$-Actin reverse: $5^{\prime}$-CAATAGTGATGACCTGG CCGT-3'

mouse xCT forward: 5'-AAGTCTAATGGGGTTGCC CT-3'

mouse xCT reverse: 5'-TGATAGCCATGGAGATGC AG-3'

rat $\beta$-Actin forward: 5'-GCCAACCGTGAAAAGA-3'

rat $\beta$-Actin reverse: 5'-GGCATACAGGGACAACA-3'

rat $\mathrm{xCT}$ forward: 5'-TCACGGGCACATAGGA-3'

rat XCT reverse: 5'-GCATAATGAGTAACTGGGTCT-3'

human $\beta$-Actin forward: 5'-ATCGTCCACCGCAAAT GCTTCTA-3'

human $\beta$-Actin reverse: $5^{\prime}$-AGCCATGCCAATCTCAT CTTGTT-3'

human xCT forward: 5'-GGTGGTGTGTTTGCTGTC-3' human xCT reverse: 5'-GCTGGTAGAGGAGTGTGC-3' 


\section{Chromatin immunoprecipitation}

WT or $T s c 2^{-/-}$MEFs were seeded on $15-\mathrm{cm}$ plates until they reached $90 \%$ confluence. One day later, cells were treated with or without rapamycin $(10 \mathrm{nM})$ for $24 \mathrm{~h}$. Then the cells were fixed with $1 \%$ formaldehyde (final concentration) for $10 \mathrm{~min}$. The cross-linking was stopped with $0.125 \mathrm{M}$ glycine (final concentration). The cells were washed with cold PBS three times and then the cells were lyzed with $1 \mathrm{~mL}$ lysis buffer [1\% SDS, $10 \mathrm{mM}$ EDTA, 50 $\mathrm{mM}$ Tris $\bullet \mathrm{HCl}(\mathrm{pH} 8.1)$, and a protease inhibitor mixture; Roche]. Cell lysates were sonicated to shear the DNA under conditions established to ensure that the DNA fragments were 500 and $1000 \mathrm{bp}$. The sonicated samples were centrifuged and the supernatants were diluted in chromatin immunoprecipitation (ChIP) dilution buffer [0.01\% SDS, $1.1 \%$ Triton X-100, $1.2 \mathrm{mM}$ EDTA, $167 \mathrm{mM} \mathrm{NaCl}$, and $16.7 \mathrm{mM}$ Tris $\bullet \mathrm{HCl}(\mathrm{pH} 8.1)]$. The supernatants were precleared with $60 \mu \mathrm{L}$ Protein G agarose/ChIP Blocked (Millipore) for $5 \mathrm{~h}$ at $4{ }^{\circ} \mathrm{C}$. After pelleting agarose with centrifugation, $100 \mu \mathrm{L}$ of each sample was removed as total input, and the rest was then immunoprecipitated with polyclonal anti-Oct1 antibody or rabbit control IgG overnight at $4{ }^{\circ} \mathrm{C}$ on a rotating wheel. The immunocomplexes were mixed with $40 \mu \mathrm{L}$ Protein $\mathrm{G}$ agarose/ChIP blocked for $1 \mathrm{~h}$ with rotation at $4{ }^{\circ} \mathrm{C}$. The agarose beads with immunocomplexes were washed in order once with ChIP low-salt wash buffer [0.1\% SDS, $1 \%$ Triton X-100, 2 mM EDTA, $20 \mathrm{mM}$ Tris $\bullet \mathrm{HCl}(\mathrm{pH} 8.1)$, and $150 \mathrm{mM} \mathrm{NaCl}$ ], ChIP highsalt wash buffer $[0.1 \%$ SDS, $1 \%$ Triton $\mathrm{X}-100,2 \mathrm{mM}$ EDTA, $20 \mathrm{mM}$ Tris $\bullet \mathrm{HCl}(\mathrm{pH} 8.1)$, and $500 \mathrm{mM} \mathrm{NaCl}$, ChIP LiCl buffer $[0.25 \mathrm{M} \mathrm{LiCl}, 1 \%$ Nonidet P-40, $1 \%$ deoxycholate acid, $1 \mathrm{mM}$ EDTA and $10 \mathrm{mM}$ Tris $\bullet \mathrm{HCl}(\mathrm{pH}$ 8.1)], and twice with TE buffer [10 $\mathrm{mM}$ Tris ( $\mathrm{pH} 8.0$ ) and 1 mM EDTA]. The immunocomplexes were extracted twice with the elution buffer ( $1 \%$ SDS and $0.1 \mathrm{M} \mathrm{NaHCO}_{3}$ ). The protein-DNA cross-linking was reversed by adding $0.2 \mathrm{M}$ $\mathrm{NaCl}$ (final concentration) and incubated at $65^{\circ} \mathrm{C}$ overnight. DNA was purified by two rounds of phenol-chloroform extraction and then precipitated with ethanol. DNA were resuspended in $40 \mu \mathrm{L}$ of $\mathrm{ddH}_{2} \mathrm{O}$ and amplified by RT-PCR.

\section{qPCR analysis of ChIP DNA}

The Oct1 binding regions were predicted with the computer software Genomatix. The xCT primer was designed within the predicted binding region (PBR) using the computer software Primer Premier 6 (Primer Biosoft International). The no-binding region (NBR) was designed at chromosome 9 as the negative control. Amplification was run for 40 cycles using TransStart Green quantitative PCR SuperMix (TransGen Biotech). Each PCR was performed in triplicate.
The analysis of the data was described previously [8]. The primers were as follows:

PBR forward: 5'-CCGAGGAGCAAGAGGAGTAAT-3'

PBR reverse: 5'-GCAGTGTCACACCAGAGGA-3'

NBR forward: 5'-GGAACTTTCGTGCGTCTTG-3'

NBR reverse: 5'-GCTCACCTCTCCTGATTACTAC-3'

\section{Human kidney tumor assessment}

The kidney tumor and adjacent normal kidney samples were obtained from the Department of Urology, Peking Union Medical College Hospital. Partial nephrectomy was performed on the right kidney of a 16-year-old female TSC patient with a frameshift mutation of TSC2 (g.10059delC, p.S132SfsX50). Samples were freshly obtained from a resected angioleiomyolipoma for immunoblotting. All the procedures were performed under the permission of the Peking Union Medical College Hospital Ethics Board.

\section{Characterization of Tsc1 pituitary knockout mice}

To generate mice with Tsc1 pituitary knockout mice (Ghrhr-cre; Tscl $l^{\text {LoxP/LoxP }}$ ), we bred Tscl $l^{\text {LoxP/LoxP }}(129 \mathrm{~S} 4 /$ SvJae) mice with $\mathrm{Tg}(($ Ghrhr-cre $) 3242 \mathrm{Lsk} / \mathrm{J})$ (FVB) mice (Jackson Laboratory, Bar Harbor, ME, USA) [46]. Mice were maintained in the mixed (129S4/SvJae; FVB) genetic background. Beginning at the age of 12 months, Ghrhr-cre; $T s c 1^{\text {LoxP/LoxP }}$ mice and their wild-type siblings were given either $2 \mathrm{mg} / \mathrm{kg}$ rapamycin or vehicle i.p. 3 times per week for 3 months. Tissues were frozen in liquid nitrogen and stored at $-80^{\circ} \mathrm{C}$ for immunoblotting later on. The animal protocol was approved by the Animal Center of the Institute of Basic Medical Sciences, Chinese Academy of Medical Sciences (CAMS) and Peking Union Medical College (PUMC), and was compliant with the regulation of Beijing Administration Office of Laboratory Animal on the care of experimental animals.

\section{Generation of Tsc1 skin knockout mice}

Mice bearing the KRT14-cre allele (B6. STOCK $\mathrm{Tg}$ (KRT14-cre)1Amc/NJU) were obtained from Jackson Laboratories. These mice were crossmated with $T_{s c} l^{\text {LoxP/LoxP }}$ (129S4/SvJae) mice [10]. The offsprings were then crossed back with $T s c 1^{\text {LoxP/LoxP }}$ mice, getting the $T s c l$ skin knockout mice (Tscl-sKO).

\section{SASP and rapamycin treatment of Tsc1 skin knockout mice}

Four-week-old Tsc1 skin knockout mice were treated with $350 \mathrm{mg} / \mathrm{kg}$ SASP freshly diluted in $15 \%$ DMSO via i.p. 

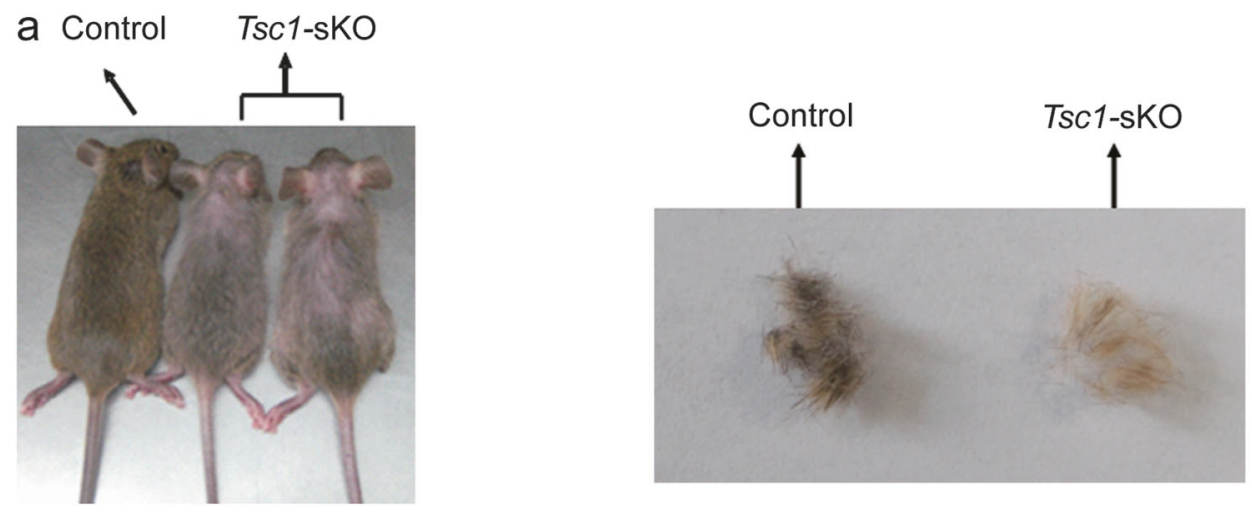

b

Control
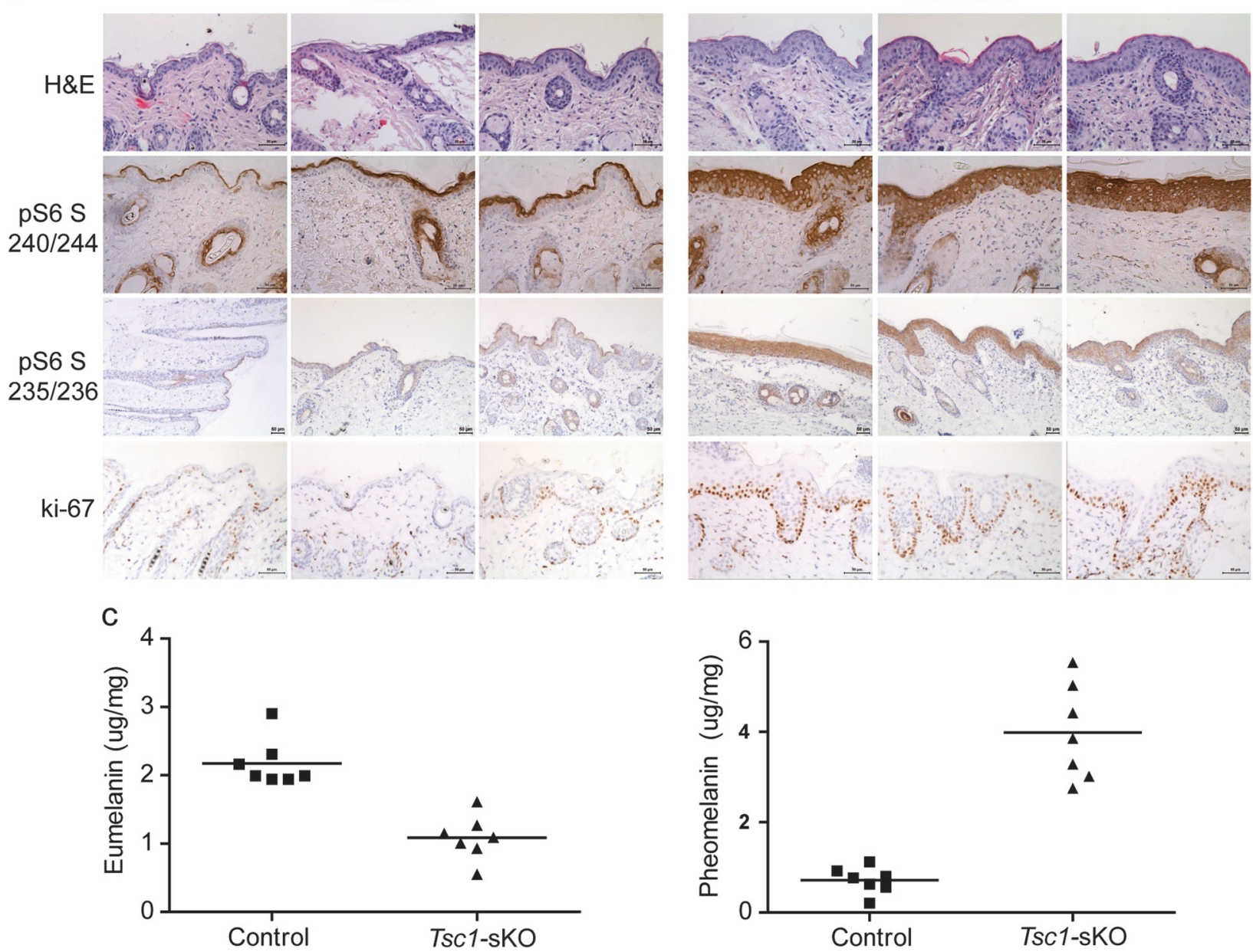

Fig. 1 Loss of $T s c 1$ promotes mTOR activation and cell proliferation and compromises melanin metabolism. a Eleven-week-old mice (left) and their furs (right). b The skins of 5 to 10-week control and Tsc1sKO mice were stained with hematoxylin-eosin, anti-pS6 (S240/244),

injection 3 times per week for 4 weeks. Seven-week-old Tsc1 skin knockout mice were treated with $1 \mathrm{mg} / \mathrm{kg}$ rapamycin diluted in $0.25 \%$ PEG plus $0.25 \%$ Tween- 80 via i.p. injection 3 times per week for 4 weeks. Skins were harvested for histology study and measurement of eumelanin and pheomelanin.

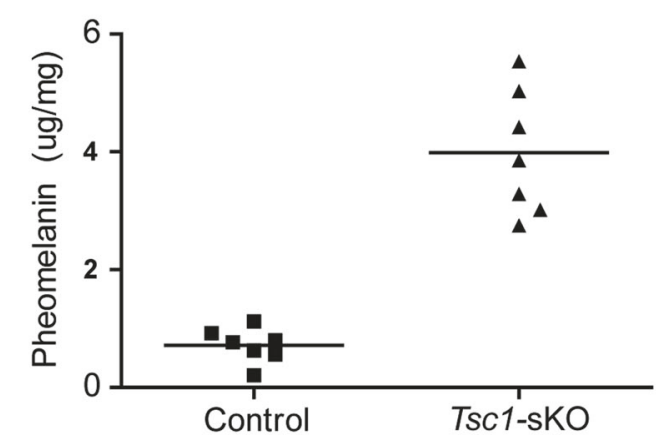

and ki-67 antibodies. (Scale bars: $50 \mu \mathrm{m}$ ). c The concentration of eumelanin (left) and pheomelanin (right) of 15-month mouse skin was measured by HPLC. $n=7$

\section{Histology study}

Skin tissues of WT and Tscl-sKO, and skin tissues from Tscl-sKO mice treated with SASP or rapamycin were fixed in $10 \%$ formaldehyde and embedded in paraffin. Skin sections were stained with $\mathrm{H} \& \mathrm{E}$ following the standard 
protocols. Immunohistochemistry for detection of phosphor-S6 (S240/244) and ki-67 (EPITOMICS, Burlingame, CA, USA) was performed according to standard protocol.

\section{Measurement of eumelanin (PTCA) and pheomelanin (4-AHP)}

Skin tissue was flushed with normal saline, blotted dried, and weighed. One hundred milligrams of the tissues were homogenized in $0.2 \mathrm{~mL}$ of lysis buffer $(100 \mathrm{mM}$ Tris- $\mathrm{HCl}$ pH 7.6, $500 \mathrm{mM} \mathrm{LiCl,} 10 \mathrm{mM}$ EDTA, 5 mM DTT, 1\% SDS) and then incubated in a water bath at $37^{\circ} \mathrm{C}$ for $6 \mathrm{~h}$. Afterwards, homogenate was centrifuged at $12000 \mathrm{rpm}$ for $5 \mathrm{~min}$ and the supernatant was collected and stored at $-80{ }^{\circ} \mathrm{C}$ for Eumelanin (PTCA) and Pheomelanin (4-AHP) assay (Figure $\mathrm{S} 1$ ). For PTCA assay, $\mathrm{H}_{2} \mathrm{O}_{2}$ oxidation was performed as described previously [47]. Briefly, resulted residues were dissolved with $100 \mu \mathrm{l}$ mobile phase and filtered through a nylon membrane $(13 \mathrm{~mm}, 0.22 \mu \mathrm{M}$, Jinlong, Shanghai, China) before $10 \mu \mathrm{l}$ sample was analyzed by an Agilent 1260 infinity LC system (Santa Clara, CA, USA). For 4-AHP assay, hydriodic acid reduction of tissue samples was performed as previously reported [48]. The dried samples were reconstituted in an acetonitrile: water mixture $(1: 9,200 \mu \mathrm{l})$ and filtered through a nylon membrane before $10 \mu \mathrm{l}$ sample was analyzed by an Agilent 1260 infinity LC system. The typical chromatogram of PTCA and 4-AHP was shown in Table S1 and Figure S2.

\section{Tumorigenesis and combination treatment of SASP and rapamycin}

Subcutaneous tumors were established as described previously [7, 8, 43]. Immunodeficient nude mice (strain BALB/c, 6-8 weeks old) were obtained from the Institute of Laboratory Animal Sciences, CAMS and PUMC. Eight female mice were used in each cohort. Tumor growth and mouse survival were assessed after s.c. inoculation of $1 \times$ $10^{6}$ Pten $^{-/-}$MEFs or ELT3 cells with shRNA vector or $\operatorname{sh} x C T$ in $100 \mu \mathrm{l}$ DMEM into the right posterior flank region.

For combination treatment of the xenografting tumor, $1 \times 10^{6}$ ELT3 cells were subcutaneously inoculated into 28 female nude mice, tumors were allowed to grow for 2 weeks until the tumor volumes reached $60-100 \mathrm{~mm}^{3}$. The animals were randomly divided into four different groups for single treatment or combination treatment with seven mice per group. The freshly made SASP diluted in PBS and rapamycin $(4 \mathrm{mg} / \mathrm{mL}$ stock in ethanol) diluted in $0.25 \%$ PEG plus $0.25 \%$ Tween- 80 were injected i.p. 3 times per week at $350 \mathrm{mg} / \mathrm{kg}$ and $0.02 \mathrm{mg} / \mathrm{kg}$, respectively. Tumor growth was measured and normalized to the initial tumor volumes.

\section{Statistical analysis}

Mouse tumor development and mouse survival were analyzed by using the Kaplan-Meier log-rank test with GraphPad Prism software. Other data were analyzed with $t$ test. When $P$ value $<0.05$, differences were considered significant.

\section{Results}

\section{Hyperactivated mTOR promotes mouse skin cell proliferation and compromises melanin metabolism}

TSC is featured with lesions in multiple organs, including hypopigmented macules [30]. To test the hypothesis that hyperactive mTOR was responsible for hypopigmented macules in the skin of TSC patients, we first generated skinspecific Tscl conditional knockout mice by using Cre-LoxP system. Mice bearing KRT14-cre allele were bred with $T s c 1^{\text {LoxP/LoxP }}$ mice. The offsprings were then back-crossed with $T s c 1^{\text {LoxP/LoxP }}$ mice, getting the $T s c l$ skin knockout mice (Tsc1-sKO). Lighter color of fur (Fig. 1a), thicker epidermis, and stronger staining of phosphor-S6 (a biomarker of mTOR activation) and ki-67 (Fig. 1b) in the skin were found in Tscl-sKO mice, in comparison with WT mice. Less eumelanin and more pheomelanin (Fig. 1c) were in the skin of Tscl-sKO mice than in that of WT mice. Therefore, loss of Tsc1 activates mTOR, promotes cell proliferation and disrupts melanin metabolism.

\section{mTOR is a positive regulator of $\mathrm{XCT}$ expression}

To identify the mechanism of how activation of mTOR enhances pheomelanin production and inhibits eumelanin synthesis, we profiled differential gene expression between $T s c 2^{-/}$and WT MEFs. We found that XCT mRNA was increased and sensitized to mTOR inhibitor rapamycin in Tsc $2^{-/-}$MEFs (Table 1). xCT is a plasma membrane amino acid antiporter and is critical for melanin synthesis [36]. The increased expression of XCT mRNA and protein in $T s c 2^{-1-}$ or Pten $^{-1-}$ MEFs was reversed by rapamycin (Fig. 2a, b). Ectopic expression of human TSC2 reduced xCT mRNA and protein in rat uterine leiomyoma-derived Tsc2-null

Table 1 xCT mRNA is increased in TSC2-null cells

\begin{tabular}{|c|c|c|c|c|}
\hline \multirow[t]{2}{*}{ Gene } & \multicolumn{2}{|c|}{$T s c 2^{-1-}$ vs. WT } & \multicolumn{2}{|c|}{$T s c 2^{-/-} \mathrm{R}$ vs. $T s c 2^{-/-}$} \\
\hline & Fold change & Description & Fold change & Description \\
\hline $\mathrm{xCT}$ & 7.90264 & Up & -13.9908 & Down \\
\hline
\end{tabular}

The mRNA abundance of xCT in WT, $T s c 2^{-/-} \mathrm{MEFs}$, and $T s c 2^{-/-}$ MEFs treated with rapamycin (R) was measured using Affymetrix mouse genome 4302.0 array 
a
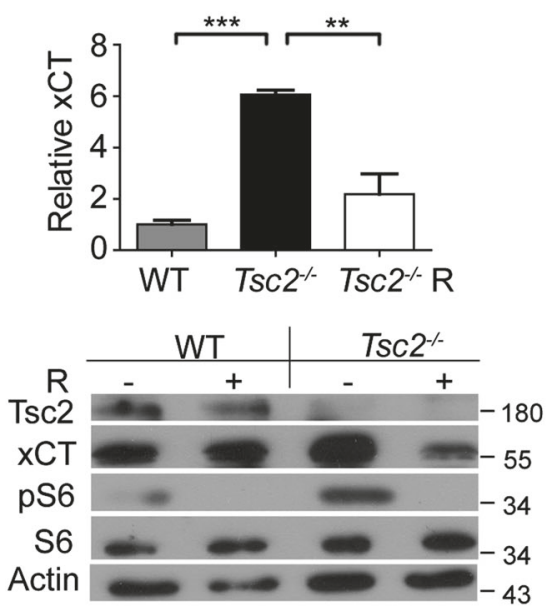

d
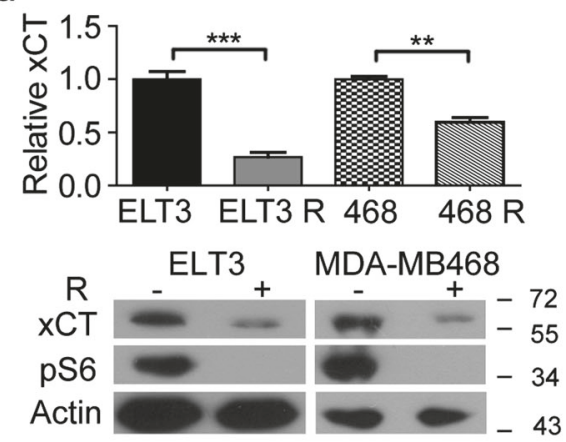

g
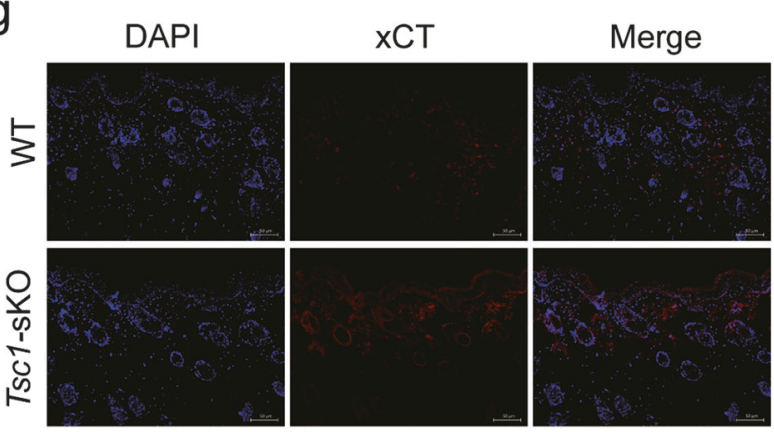

Fig. 2 mTOR is a positive regulator of xCT expression. a-d RT-qPCR in triplicate and immunoblotting analysis of mRNA and protein. mRNA data are presented as means \pm SEM. $* P<0.05$. $* * P<0.01$, $* * * P<0.001$. WT, Tsc2 $2^{-1-}$ (a), or Pten $^{-1-}$ (b) MEFs treated with or without $10 \mathrm{nM}$ rapamycin $(\mathrm{R})$ for $24 \mathrm{~h}$ were analyzed. $\mathrm{c} \mathrm{xCT}$ in $T s c 2-$ null ELT3 cell line and its human TSC2 revertant. d ELT3 and human breast cancer cell line DA-MB 468 were treated with or without $10 \mathrm{nM}$ rapamycin for $24 \mathrm{~h}$. e Kidney tumor tissue ( $\mathrm{T}$ ) and adjacent normal

ELT3 cell line (Fig. 2c). Rapamycin also decreased xCT mRNA and protein in ELT3 cell line and human breast cancer cell line MDA-MB 468 (Fig. 2d). xCT and mTOR

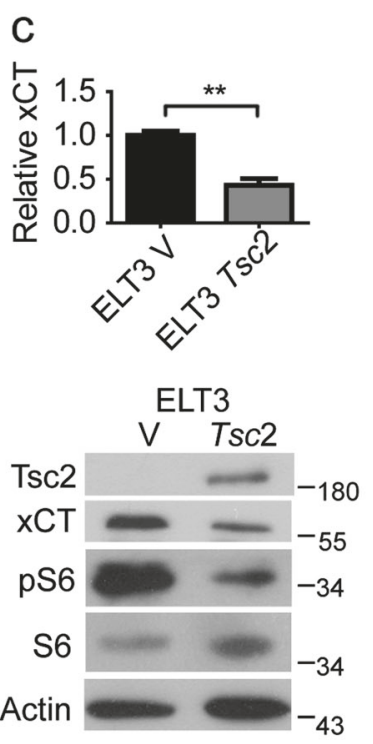

f

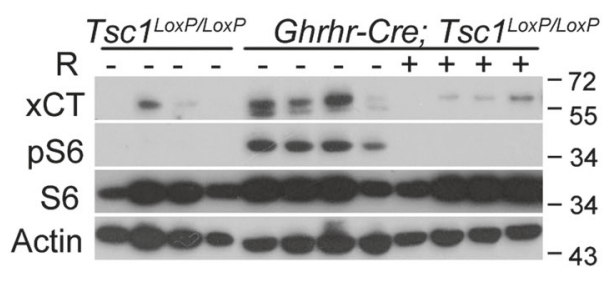

$h$

$\mathrm{h}$

Pten-1-

i

Pten $^{-1}$
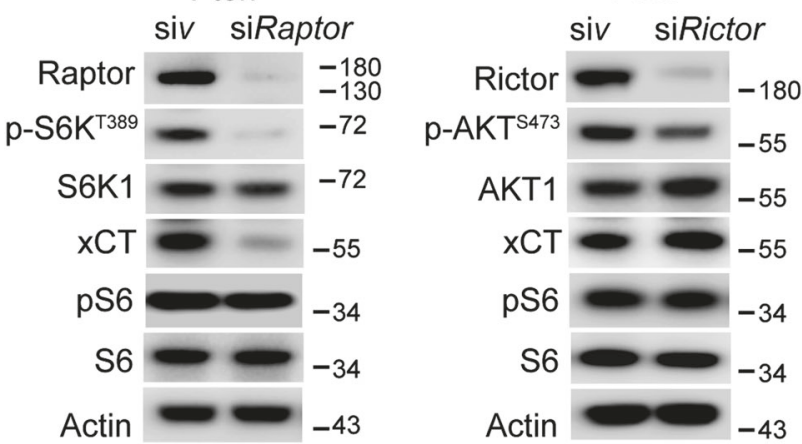

tissue $(\mathrm{N})$ from a TSC patient were immunoblotted. f Immunoblotting of the pituitary glands of control and Ghrhr-Cre; Tsc1 $1^{\text {LoxP/LoxP }}$ mice treated with or without rapamycin (R). $\mathbf{g}$ Immunofluorescence staining for xCT (red) in WT and Tscl-sKO mouse skins. Nuclei were stained with DAPI (blue). (Scale bars: $50 \mu \mathrm{m})$. Pten $^{-1}$ MEFs were transfected with small interfering RNA against Raptor (h) or Rictor (i) for $48 \mathrm{~h}$ and then harvested for immunoblotting

effector phosphor-S6 were much higher in human kidney angiomyolipoma tissue caused by TSC 2 mutation, compared with the adjacent kidney tissue (Fig. 2e). Tsc1 


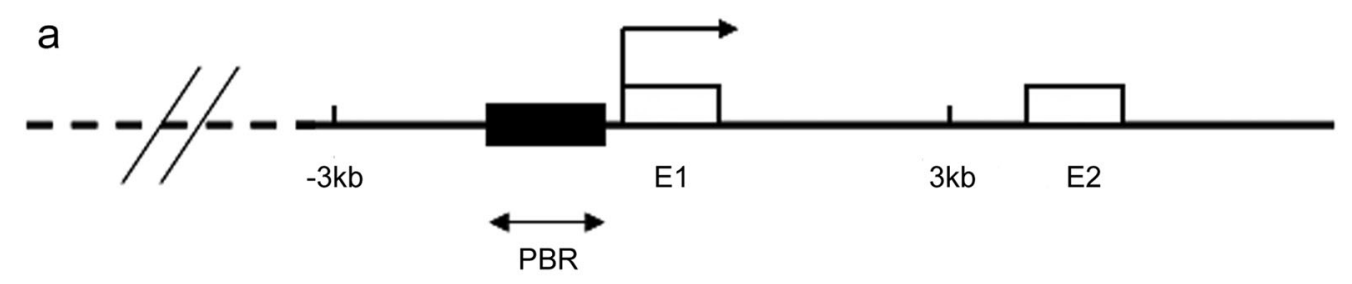

b

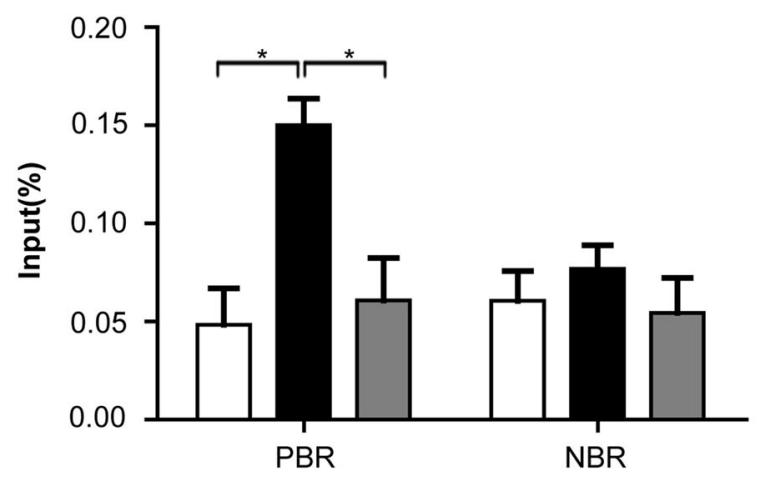

C<smiles>[CH]</smiles>
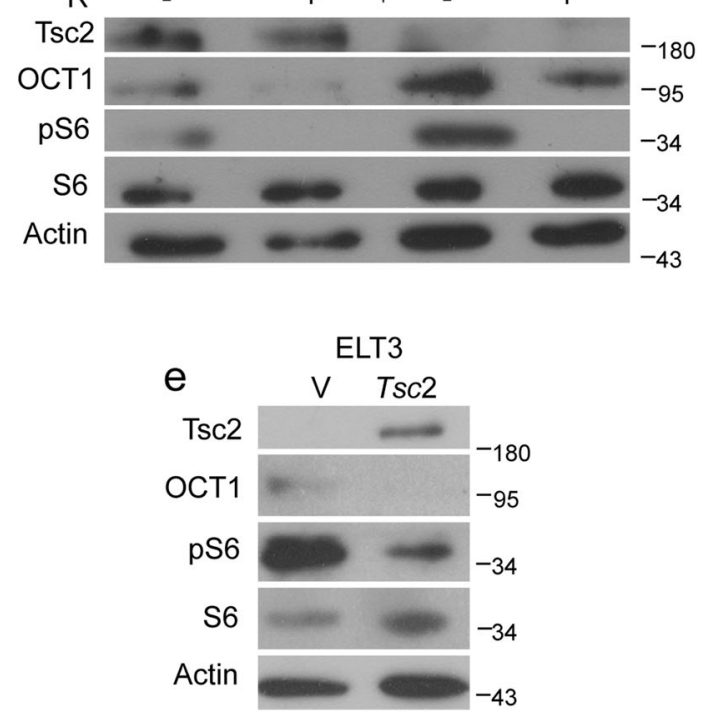

Fig. 3 mTORC1 stimulates $\mathrm{xCT}$ expression through induction of Oct1. a Schematic representation of the promoter of mouse $S l c 7 a 11$ gene. E1 and E2, Slc7a11 exon 1 and 2; dark rectangle, predicted Oct1 binding region; PBR, predicted binding region; NBR, nonspecific binding region; two-way arrows, fragments amplified in ChIP real-time PCR analysis. The transcription start site is indicated by an arrow above the gene. b $T s c 2^{-1-}$ MEFs treated with or without $10 \mathrm{nM}$ rapamycin (R) for $24 \mathrm{~h}$. Oct1 antibody-precipitated DNA was PCR amplified for regions indicated in A. NBR was negative control region in

pituitary knockout mice (Ghrhr-Cre; Tscl $\left.{ }^{\text {LoxP/LoxP }}\right)$ were generated by crossing Ghrhr-Cre mice with $T s c 1^{\text {LoxP/LoxP }}$ mice [46]. Loss of Tsc1 in pituitary potentiated mTOR signaling and $\mathrm{xCT}$ expression (Fig. 2f). Rapamycin treatment of Tsc1 pituitary knockout mice abolished both phosphor-S6 and xCT (Fig. 2f). In skin-specific Tscl conditional knockout mice, xCT expression was higher than
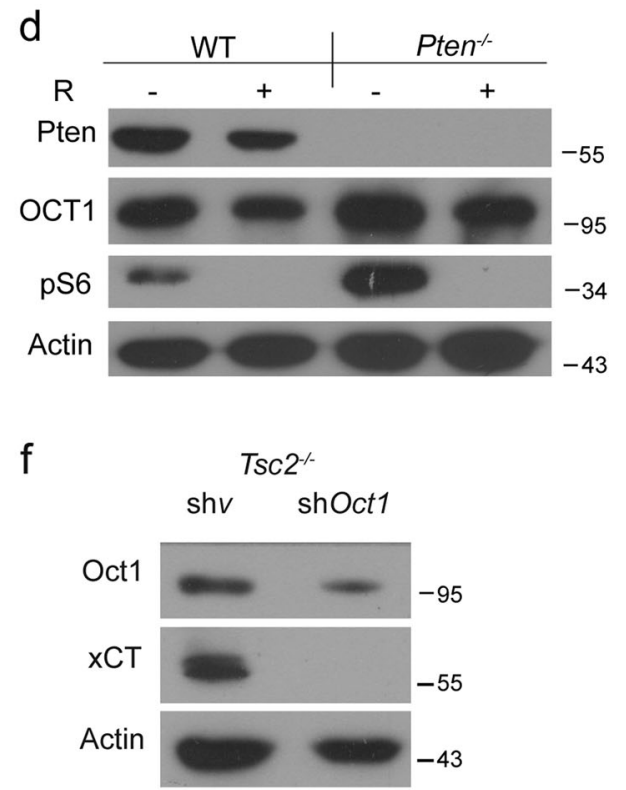

Chromosome 9. The data are plotted as the ratio of immunoprecipitated DNA subtracting nonspecific binding to IgG vs. total input DNA. Representative data from two independent experiments are shown. Data represent mean \pm SEM of replicate real-time PCR. $* P<0.05$. Immunoblotting analysis for WT and $\mathrm{Tsc}^{-/-}$(c), or $\mathrm{Pten}^{-/-}$(d) MEFs treated with or without $10 \mathrm{nM}$ rapamycin (R) for $24 \mathrm{~h}$. e Immunoblotting of ELT3 cell line and its human TSC2 revertant. f Tsc2 ${ }^{-1-}$ MEFs were transfected with shOctl or scramble $\operatorname{shRNA}(\operatorname{sh} v)$ in GPU6/Hygro vector and then subjected to immunoblotting

that in control mice (Fig. 2g). These data suggest that mTOR stimulates $\mathrm{xCT}$ expression.

mTOR exists in two multiprotein complexes, rapamycinsensitive mTORC1 and rapamycin-insensitive mTORC2 [49]. To dissect which mTOR complex is responsible for the overexpression of $\mathrm{xCT}$, we knocked down raptor and rictor, respectively, in $\mathrm{Pten}^{-1-}$ MEFs. xCT decreased in 
Fig. 4 mTOR suppresses melanin synthesis. a, b Skins were harvested from the $T s c 1$ sKO mice which were treated with either rapamycin (Rapa), or SASP for 4 weeks at the age of 7 or 4 weeks, respectively.

Vehicle PEG/DMSO was served as control. The concentration of eumelanin (a) and pheomelanin (b) was measured by HPLC. Rapamycin treated mice, $n=6$, SASP-treated mice, $n=4$
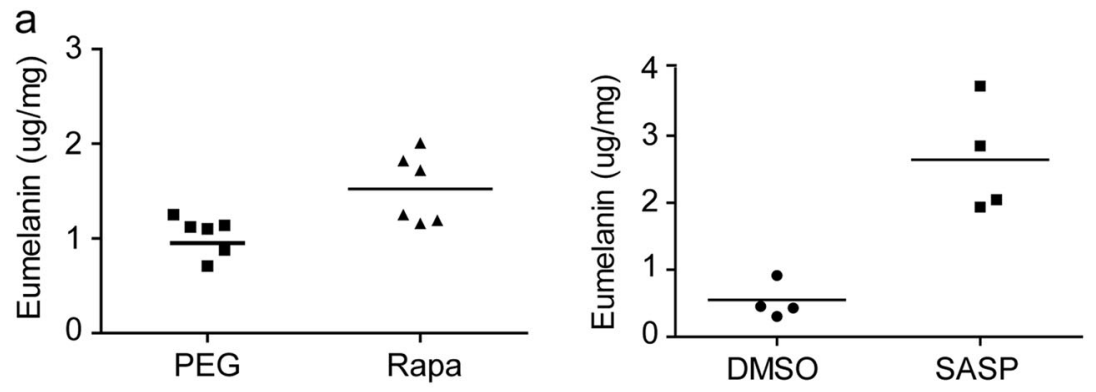

b

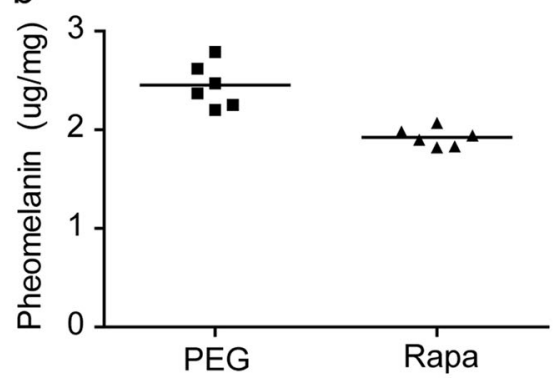

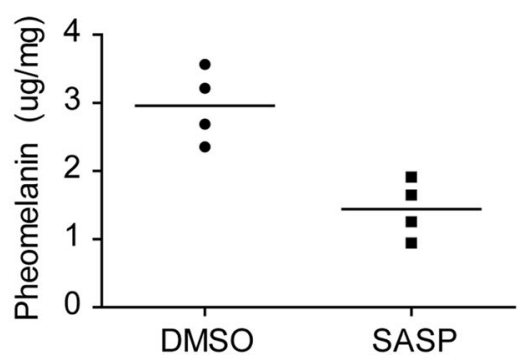

raptor depleting cells but not in rictor depleting cells (Fig. 2h, i). Therefore, xCT expression is activated by mTORC1.

\section{mTORC1 stimulates XCT expression through induction of Oct1}

Since mTOR activation of $\mathrm{xCT}$ expression is likely at transcriptional level, we checked the potential binding sites in the promoter region of mouse Slc7all gene that encodes $\mathrm{xCT}$. As a member of the POU transcription factor family, Oct1 controls the expression of multiple genes by directly binding to a conserved sequence (ATGCWAAT, W can be A or T) in these genes. A potential binding site for Oct1 was identified by the computer software program Genomatix (Fig. 3a). Real-time PCR analysis of ChIP DNA revealed that the binding of Oct1 to a DNA region immediately upstream of exon 1 of Slc7all gene was significantly higher in $T s c 2^{-/-}$MEFs than in WT cells. The interaction between Oct1 and Slc7all promoter was disrupted by rapamycin treatment (Fig. 3b). Since Oct1 was a transcriptional activator of Slc7all gene, we predicted that Oct1 was a link between mTORC1 activation and xCT expression. Oct1 was indeed increased at mRNA and protein levels in the cells with mTOR hyperactivation due to either Tsc2 or Pten deficiency, and were reduced after rapamycin treatment (Fig. 3c, d). Restoration of TSC2 led to reduction of Oct1 expression in ELT3 cell line (Fig. 3e). In addition, knockdown of Oct 1 dramatically reduced xCT expression in $T s c 2^{-/-}$MEFs (Fig. 3f), indicating that mTORC1 activates $\mathrm{xCT}$ expression through upregulation of Oct1 expression.

\section{Suppression of mTOR-xCT cascade normalizes melanin metabolism of Tsc1 knockout mouse skin}

To check whether aberrant activation of mTOR-xCT signaling cascade is responsible for hypopigmentation of Tsc1 deficient mouse skin, we treated Tscl-sKO mice with mTOR inhibitor rapamycin or xCT inhibitor SASP. Either rapamycin or SASP increased eumelanin concentration (Fig. 4a) and reduced pheomelanin abundance (Fig. 4b) of Tscl-sKO mice. However, fur color of Tscl-sKO mice treated with either rapamycin (Figure S3A) or SASP (Figure S3B) was not obviously different from that of $T s c 1$-sKO mice treated with solvent. Lighter staining of pS6 and ki-67 in skin were found in rapamycin treated $T s c 1$-sKO mice (Figure S3C), but not in SASP treated Tscl-sKO mice (Figure S3D).

\section{Inhibition of mTOR-xCT signaling cascade induces ferroptosis and suppresses tumorigenesis}

To examine the role of mTOR upregulation of $\mathrm{xCT}$ in loss of TSC1/2 complex- or PTEN-induced tumorigenesis, we stably knocked down xCT in ELT3 and Pten $^{-/-}$MEFs. Depletion of $\mathrm{xCT}$ significantly reduced cell proliferation in vitro (Fig. 5a, b), attenuated subcutaneous tumor formation of ELT3 and Pten ${ }^{-/}$MEFs in nude mice and extended the survival of tumor-bearing mice (Fig. $5 \mathrm{c}, \mathrm{d}$ ). To test the efficacy of targeting $\mathrm{xCT}$ for therapeutic intervention of cell proliferation and tumorigenesis, we treated WT and $T s c 2^{-/-}$MEFs with SASP. $T s c 2^{-/-}$MEFs were more sensitive to SASP treatment than WT MEFs (Fig. 6a). xCT inhibition causes a ROS-dependent cell death called 
Fig. 5 Depletion of $\mathrm{xCT}$ suppresses cell proliferation and tumorigenesis. ELT3 cells (a) or Pten $^{-/-}$MEFs (b) stably expressing the shRNA for $\mathrm{xCT}$ or scramble shRNA were checked by immunoblotting for efficiency of xCT depletion in triplicate. The proliferation of these cells was then determined by counting viable cell numbers for up to 3 days. $* * * P<0.001$. Data are presented as means \pm SEM. ELT3 (c) or Pten ${ }^{-/-}$(d) cells stably expressing the $\operatorname{sh} v$ or sh $x C T$ were subcutaneous injected into the nude mice for analysis of tumor initiation (left) and the survival of tumorbearing mice (right). $n=7 . * P$ $<0.05$, $* * * P<0.001$. Data are presented as means \pm SEM a

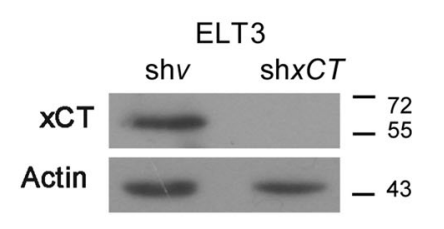

b
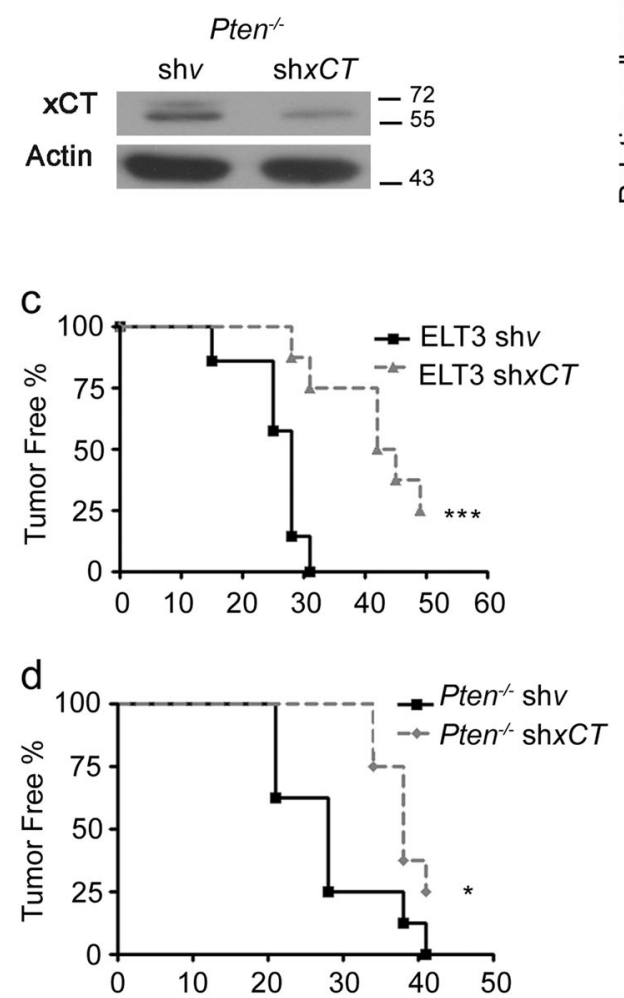
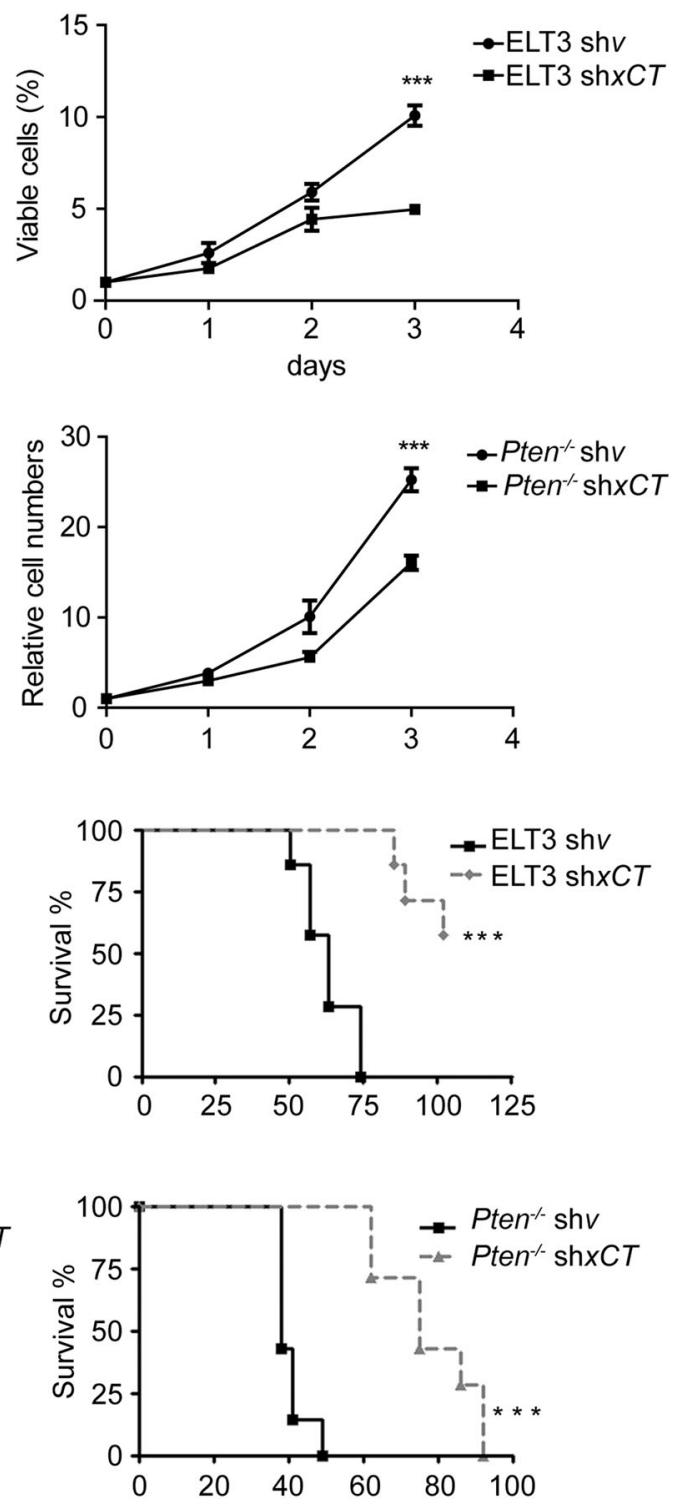

ferroptosis [50]. We found that $\mathrm{xCT}$ inhibition by SASP increased ROS in $T s c 2^{-/-}$MEFs (Fig. 6b). Furthermore, antioxidant agent NAC and ferroptosis inhibitor Ferr-1 alleviated the cell death caused by SASP (Fig. 6c, d). In contrast, neither apoptosis inhibitor Z-VAD-FMK (Fig. 6e) nor necrosis inhibitor Nec-1 (Fig. 6f) relieved SASPmediated cell death. Tsc $2^{-/-}$MEFs were also more sensitive to rapamycin treatment than WT MEFs (Fig. 7a). Combination of rapamycin and SASP exerted synergistic suppression on proliferation of $T s c 2^{-1-}$ MEFs (Fig. 7b). These in vitro findings prompted us to test the efficacy of this combinatory strategy in vivo. A tumor model was established by subcutaneous injection of ELT3 cells into nude mice. Peritoneal injection of rapamycin or SASP compromised tumor development. Combined rapamycin and SASP treatment achieved greater suppression of tumor formation than single drug application (Fig. 7c). These data suggest that the proliferation of these mTOR-activated cells is dependent on mTOR/xCT axis, and mTOR-xCT signaling cascade plays an important role in melanin synthesis. These features could therefore be explored for the treatment of tumors and melanin synthesis disorder caused by deregulated mTOR signaling.

\section{Discussion}

mTOR signaling pathway plays an important role in regulation of cell growth and proliferation [51]. In this study, we found that $\mathrm{xCT}$ was over-expressed in mTOR suppressor $T s c 2$ or Pten knockout cells, as well as Tsc1 or Tsc2-deficient tissues. Augmented mTOR-xCT axis disrupted melanin synthesis and potentiated oncogenesis (Fig. 7d). 

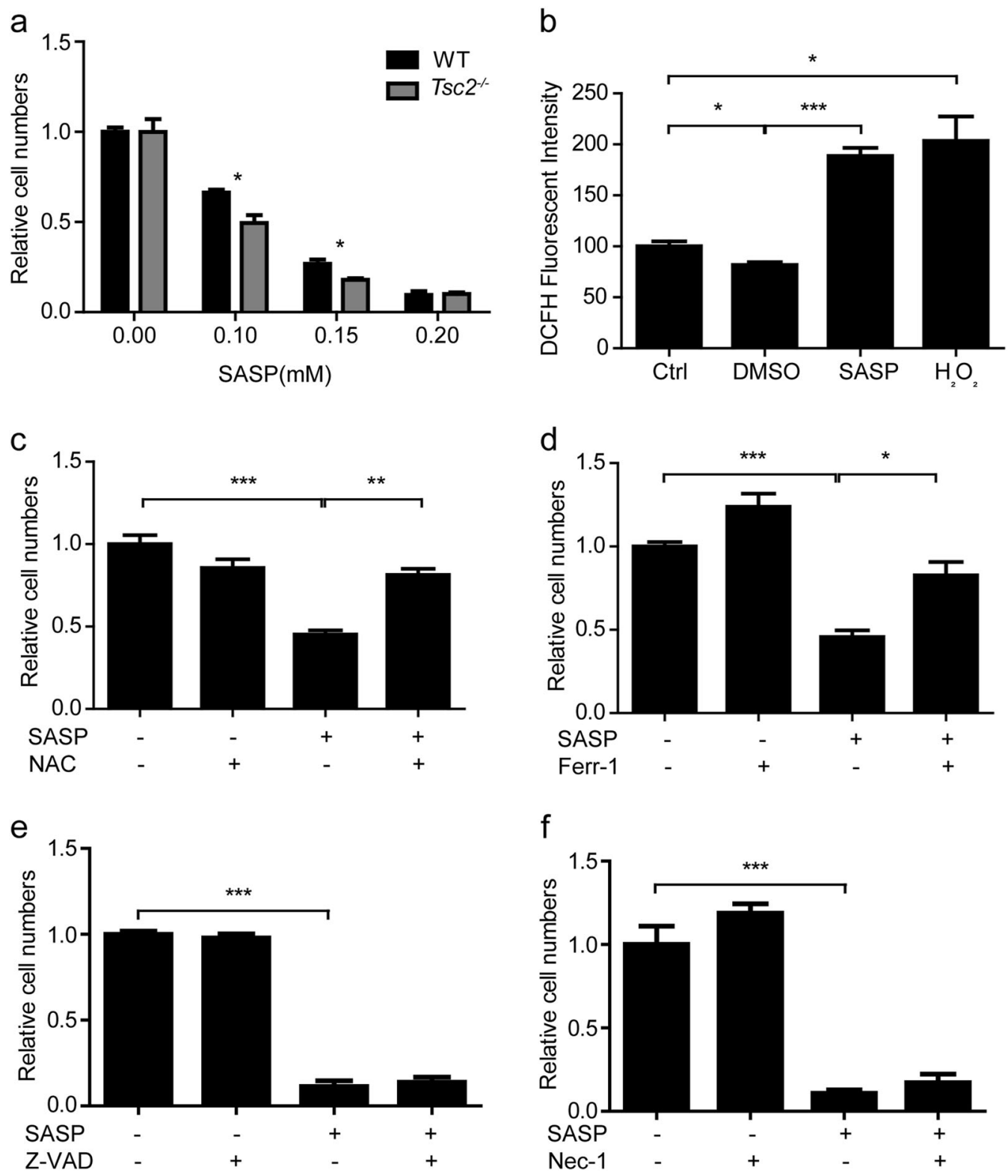

Fig. 6 xCT inhibition causes ferroptosis. a WT and $T s c 2^{-1-}$ MEF cells were treated with SASP for $48 \mathrm{~h}$ at the indicated concentration in triplicate. Cell viability was determined by counting viable cell numbers. b $T s c 2^{-1-}$ MEF cells were treated with SASP or its solvent DMSO. ROS levels were detected with DCFH-DA and flow cytometry. Ctrl: no treatment control; $\mathrm{H}_{2} \mathrm{O}_{2}$ : positive control. Cell counting

of $T s c 2^{-/-}$MEF cells treated with $0.15 \mathrm{mM}$ SASP combined with $5 \mathrm{mM}$ NAC (c) or $2 \mathrm{uM}$ Ferr-1 (d) for $48 \mathrm{~h}$. Cell counting of $T s \mathrm{~s} 2^{-1-}$ MEF cells treated with $0.5 \mathrm{mM}$ SASP combined with $2 \mu \mathrm{M}$ Z-VADFMK (e) or $5 \mu \mathrm{M} \mathrm{Nec}-1$ (f) for $48 \mathrm{~h}$. $* P<0.05$, $* * P<0.01$, $* * * P<$ 0.001 . Data are presented as means $\pm \mathrm{SEM}$

Although $\mathrm{xCT}$ is highly expressed in some cancers [41, $52,53]$, its regulatory mechanism is largely unknown. We observed that $\mathrm{xCT}$ expression was augmented in $T s c 2^{-1-}$, $\mathrm{Tsc}^{-/-}$or $\mathrm{Pten}^{-/-}$cells and tissues, and sensitive to rapamycin treatment. Expression of $\mathrm{xCT}$ is stimulated by mTORC1 but not by mTORC2. mTOR stimulated Oct1 expression and the enhanced Oct1 then transactivated the expression of $\mathrm{xCT}$ via directly binding to the promoter of Slc7all gene. Since mTOR is probably the most frequent activated signaling pathway in cancer, mTOR-mediated

$\mathrm{xCT}$ expression through induction of Oct1 may be responsible for the $\mathrm{xCT}$ overexpression observed in many cancers.

Previous studies have shown that $\mathrm{xCT}$ is critical in the development of glioma and pancreatic cancer [52, 53]. Our data demonstrate that depletion of $\mathrm{xCT}$ suppresses cell proliferation and tumorigenesis induced by TSC 2 or PTEN deficiency. $\mathrm{xCT}$ is a plasma membrane antiporter, which moves cystine into cells in exchange for glutamate [37, 38]. The amino acid transport function of xCT may play an 


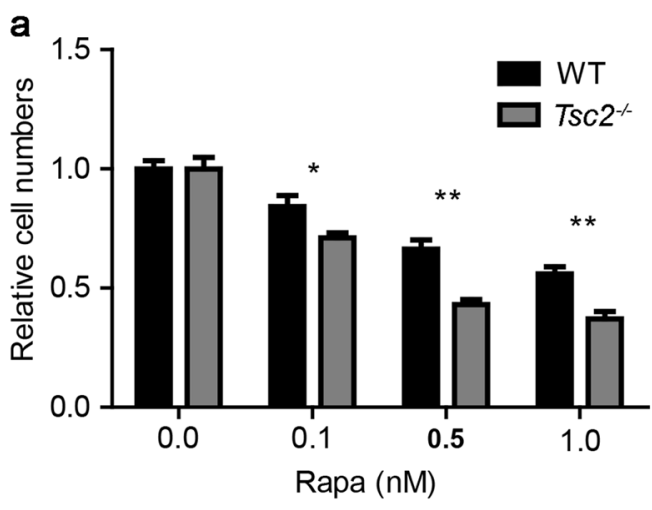

C

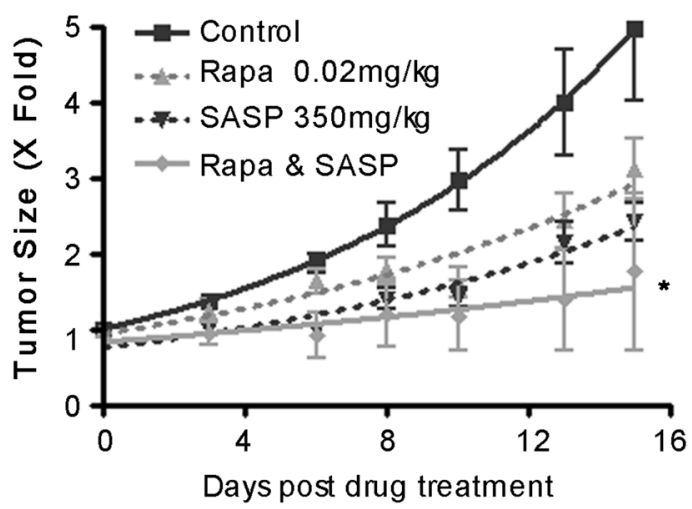

Fig. 7 Inhibition of mTOR and $\mathrm{xCT}$ suppresses cell proliferation and tumorigenesis. a WT and $T s c 2^{-/-}$MEF cells were treated with rapamycin (Rapa) for $48 \mathrm{~h}$ at the indicated concentration in triplicate. Cell viability was determined by counting viable cells. $* P<0.05$, $* * P<$ 0.01 . Data are presented as means \pm SEM. b $T s c 2^{-1-}$ MEF cells were treated in triplicate with $0.5 \mathrm{nM}$ rapamycin (Rapa), $0.15 \mathrm{mM}$ SASP or $0.5 \mathrm{nM}$ rapamycin, and $0.15 \mathrm{mM}$ SASP for $48 \mathrm{~h}$. Cell viability was

important role in tumor development. Cysteine is a nonessential amino acid as it can be synthesized by liver [54]. Some cancers including leukemia and lymphoma cannot synthesize cysteine [40, 41], due to lack of cystathionase [55], which is needed in the final step of cysteine synthesis. Thus, some tumors may rely on cystine/cysteine from microenvironment for survival. When transported into cells by $\mathrm{xCT}$, cystine is rapidly reduced to cysteine as metabolic intermediates to maintain the survival and growth of the tumor. Therefore, mTOR signaling pathway may promote tumor development through xCT-mediated alteration of amino acid metabolism.

Being an inhibitor of xCT, SASP has been widely used in the treatment of chronic inflammatory diseases such as rheumatoid arthritis, ulcerative colitis, and Crohn's disease. SASP has also been used in the treatment of lymphoma and breast cancer [56, 57]. In this study, SASP inhibited cell proliferation and tumor formation of Tsc2-deficient cells, likely through induction of ferroptosis. Inhibition of $\mathrm{xCT}$ is thus a potential novel strategy for the treatment of TSC and

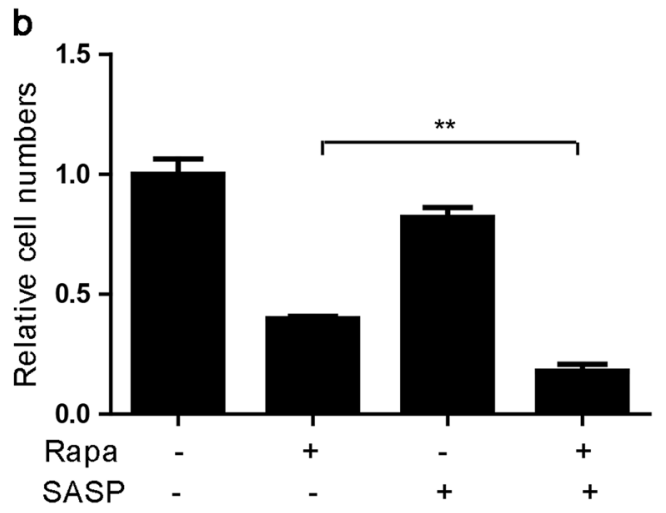

d

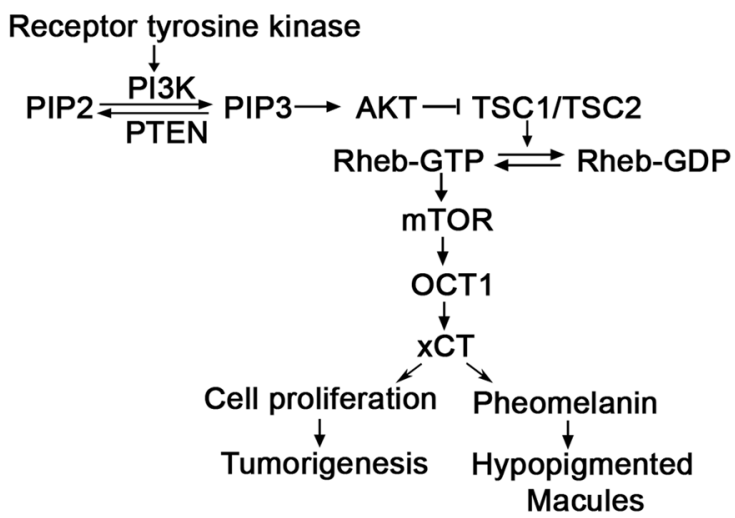

checked by counting viable cells. Combination index $<1 ; * * P<0.01$. Data are presented as means \pm SEM. c Nude mice bearing s.c. tumor of ELT3 cells were treated with rapamycin, SASP or the combination of SASP and rapamycin. The relative tumor sizes were plotted and the data represent mean \pm SEM. $n=6-7$. $* P<0.05$. d Schematic illustration of mTOR-Oct1-xCT signaling cascade control cell proliferation and melanin metabolism

other tumors induced by oncogenic mTOR. The old drug, SASP, may be repurposed for the treatment of hyperactive mTOR-mediated diseases, such as TSC. mTOR not only regulates xCT but also modulates other effectors. Besides mTOR, xCT may be modulated by other regulators. Therefore, combination treatment of rapamycin and SASP exerted a synergistic suppression of tumor development.

As a first visible sign of TSC, hypopigmented macules might be caused by abnormal melanogenesis. A recent study shows that mTOR disruption of melanogenesis through AKT/GSK3 $\beta / \beta$-catenin/MITF axis [58]. Hypopigmented macules are alleviated in TSC patients treated with mTOR inhibitors $[59,60]$. In mammals, the pigment melanin can be classified as eumelanin and pheomelanin. xCT is a major regulator of melanin synthesis. After transported into the cells by $\mathrm{xCT}$, cystine is rapidly reduced to cysteine [38]. Cysteine switches eumelanin synthesis to pheomelanin production by conjugating with dopaquinone to become intermediates of pheomelanin $[61,62]$. We present here that the color of fur in $T s c 1$-sKO mice is lighter than that of 
control mice. Hyperactive mTOR enhances pheomelanin production and inhibits eumelanin synthesis in the skin of Tscl-sKO mice. mTOR and xCT inhibitors reverse eumelanin synthesis. mTOR upregulation of $\mathrm{xCT}$ alters melanin synthesis in mice and thus may cause hypopigmented macules in patients. Notably, hypopigmented macules are by nature not tumors. As xCT promotes tumorigenesis and alters melanin synthesis, the relationship between tumorigenesis and hypopigmented macules in TSC patients are to be studied. The aberrant mTOR-Oct1-xCT signaling pathway nevertheless contributes to hypopigmented macules and tumors with abnormally differentiated cells in TSC.

In conclusion, mTOR stimulates Oct1 transactivation of xCT. mTOR-Oct1-xCT signaling cascade is essential for cell proliferation, tumor growth and pheomelanin production. The components in this cascade may be targeted for the treatment of tumor and other lesions caused by abnormal mTOR signaling propagation. Since SASP is an existing old drug, this XCT inhibitor may be readily tested for its efficacy for the treatment of TSC and other related diseases.

Acknowledgments The study was supported by National Basic Research Program of China 973 Program Grants (2015CB553802), National Key Research and Development Program of China (2016YFC0905101 and 2018YFA0506903), National Science and Technology Major Projects for Major New Drugs Innovation and Develop (2018ZX09711003-004-002), National Natural Science Foundation of China (81572463 and 81730078), Ministry of Education of China 111 Project B08007, the Chinese Academy of Medical Sciences Initiative for Innovative Medicine (2016-I2M-1-001 and 2016-I2M-1-002), and Tsinghua University Initiative Scientific Research Program (20161080086).

\section{Compliance with ethical standards}

Conflict of interest The authors declare that they have no conflict of interest.

Publisher's note: Springer Nature remains neutral with regard to jurisdictional claims in published maps and institutional affiliations.

\section{References}

1. Betz C, Hall MN. Where is mTOR and what is it doing there? J Cell Biol. 2013;203:563-74.

2. Laplante M, Sabatini DM. mTOR signaling in growth control and disease. Cell. 2012;149:274-93.

3. Cully M, You H, Levine AJ, Mak TW. Beyond PTEN mutations: the PI3K pathway as an integrator of multiple inputs during tumorigenesis. Nat Rev Cancer. 2006;6:184-92.

4. Thomas GV. mTOR and cancer: reason for dancing at the crossroads? Curr Opin Genet Dev. 2006;16:78-84.

5. Manning BD, Cantley LC. AKT/PKB signaling: navigating downstream. Cell. 2007;129:1261-74.

6. Yang Q, Guan KL. Expanding mTOR signaling. Cell Res. 2007; 17:666-81.

7. Ma J, Meng Y, Kwiatkowski DJ, Chen X, Peng H, Sun Q, et al. Mammalian target of rapamycin regulates murine and human cell differentiation through STAT3/p63/Jagged/Notch cascade. J Clin Invest. 2010;120:103-14.

8. Sun Q, Chen X, Ma J, Peng H, Wang F, Zha X, et al. Mammalian target of rapamycin up-regulation of pyruvate kinase isoenzyme type M2 is critical for aerobic glycolysis and tumor growth. Proc Natl Acad Sci USA. 2011;108:4129-34.

9. Schlessinger J. Cell signaling by receptor tyrosine kinases. Cell. 2000;103:211-25.

10. Kwiatkowski DJ, Zhang H, Bandura JL, Heiberger KM, Glogauer $\mathrm{M}$, el-Hashemite N, et al. A mouse model of TSC1 reveals sexdependent lethality from liver hemangiomas, and up-regulation of p70S6 kinase activity in Tsc1 null cells. Hum Mol Genet. 2002;11:525-34.

11. Zhang H, Cicchetti G, Onda H, Koon HB, Asrican K, Bajraszewski N, et al. Loss of Tsc1/Tsc2 activates mTOR and disrupts PI3K-Akt signaling through downregulation of PDGFR. J Clin Invest. 2003;112:1223-33.

12. Hay N. The Akt-mTOR tango and its relevance to cancer. Cancer Cell. 2005;8:179-83.

13. Samuels Y, Ericson K. Oncogenic PI3K and its role in cancer. Curr Opin Oncol. 2006;18:77-82.

14. Sabatini DM. mTOR and cancer: insights into a complex relationship. Nat Rev Cancer. 2006;6:729-34.

15. Guertin DA, Sabatini DM. Defining the role of mTOR in cancer. Cancer Cell. 2007;12:9-22.

16. Onda H, Lueck A, Marks PW, Warren HB, Kwiatkowski DJ. Tsc2 $(+/-)$ mice develop tumors in multiple sites that express gelsolin and are influenced by genetic background. J Clin Invest. 1999;104:687-95.

17. Kobayashi T, Minowa O, Kuno J, Mitani H, Hino O, Noda T. Renal carcinogenesis, hepatic hemangiomatosis, and embryonic lethality caused by a germ-line Tsc 2 mutation in mice. Cancer Res. 1999;59:1206-11.

18. Kwiatkowski DJ, Short MP. Tuberous sclerosis. Arch Dermatol. 1994;130:348-54.

19. Jozwiak S, Kawalec W, Dluzewska J, Daszkowska J, MirkowiczMalek M, Michalowicz R. Cardiac tumours in tuberous sclerosis: their incidence and course. Eur J Pediatr. 1994;153:1557.

20. Jozwiak S, Gornicki J, Michalowicz R, Gastol P. A case of renal clear cell sarcoma in a child with tuberous sclerosis. Wiad Lek. 1993;46:846-8.

21. Short MP, Richardson EP Jr., Haines JL, Kwiatkowski DJ. Clinical, neuropathological and genetic aspects of the tuberous sclerosis complex. Brain Pathol. 1995;5:173-9.

22. Krueger DA, Northrup H. Tuberous sclerosis complex surveillance and management: recommendations of the 2012 International Tuberous Sclerosis Complex Consensus Conference. Pediatr Neurol. 2013;49:255-65.

23. Northrup H, Krueger DA. Tuberous sclerosis complex diagnostic criteria update: recommendations of the 2012 Iinternational Tuberous Sclerosis Complex Consensus Conference. Pediatr Neurol. 2013;49:243-54.

24. Henske EP, Jozwiak S, Kingswood JC, Sampson JR, Thiele EA. Tuberous sclerosis complex. Nat Rev Dis Prim. 2016;2:16035.

25. Gold AP, Freeman JM. Depigmented nevi: the earliest sign of tuberous sclerosis. Pediatrics. 1965;35:1003-5.

26. Fitzpatrick TB, Szabo G, Hori Y, Simone AA, Reed WB, Greenberg MH. White leaf-shaped macules. Earliest visible sign of tuberous sclerosis. Arch Dermatol. 1968;98:1-6.

27. Desch LW. White forelock could be early sign of tuberous sclerosis. Arch Pediatr Adolesc Med. 1996;150:651-2.

28. Jozwiak S, Schwartz RA, Janniger CK, Michalowicz R, Chmielik J. Skin lesions in children with tuberous sclerosis complex: their prevalence, natural course, and diagnostic significance. Int $\mathrm{J}$ Dermatol. 1998;37:911-7. 
29. Jozwiak S, Schwartz RA, Janniger CK, Bielicka-Cymerman J. Usefulness of diagnostic criteria of tuberous sclerosis complex in pediatric patients. J Child Neurol. 2000;15:652-9.

30. Nathan N, Wang JA, Li S, Cowen EW, Haughey M, Moss J, et al. Improvement of tuberous sclerosis complex (TSC) skin tumors during long-term treatment with oral sirolimus. J Am Acad Dermatol. 2015;73:802-8.

31. Teng JM, Cowen EW, Wataya-Kaneda M, Gosnell ES, Witman PM, Hebert AA, et al. Dermatologic and dental aspects of the 2012 International Tuberous Sclerosis Complex Consensus Statements. JAMA Dermatol. 2014;150:1095-101.

32. Fitzpatrick TB. History and significance of white macules, earliest visible sign of tuberous sclerosis. Ann N Y Acad Sci. 1991;615:26-35.

33. Tilgen W. Ultrastructure of white leaf-shaped macules in tuberous sclerosis (author's transl). Arch Dermatol Forsch. 1973;248:13-27.

34. d'Ischia M, Wakamatsu K, Napolitano A, Briganti S, GarciaBorron JC, Kovacs D, et al. Melanins and melanogenesis: methods, standards, protocols. Pigment Cell Melanoma Res. 2013;26: 616-33.

35. Ito $\mathrm{S}$, Wakamatsu $\mathrm{K}$, Ozeki $\mathrm{H}$. Chemical analysis of melanins and its application to the study of the regulation of melanogenesis. Pigment Cell Res. 2000;13(Suppl 8):103-9.

36. Chintala S, Li W, Lamoreux ML, Ito S, Wakamatsu K, Sviderskaya EV, et al. Slc7a11 gene controls production of pheomelanin pigment and proliferation of cultured cells. Proc Natl Acad Sci USA. 2005;102:10964-9.

37. Bannai S. Exchange of cystine and glutamate across plasma membrane of human fibroblasts. J Biol Chem. 1986;261:2256-63.

38. Christensen HN. Role of amino acid transport and countertransport in nutrition and metabolism. Physiol Rev. 1990;70:43-77.

39. Bannai S, Ishii T. A novel function of glutamine in cell culture: utilization of glutamine for the uptake of cystine in human fibroblasts. J Cell Physiol. 1988;137:360-6.

40. Iglehart JK, York RM, Modest AP, Lazarus H, Livingston DM. Cystine requirement of continuous human lymphoid cell lines of normal and leukemic origin. J Biol Chem. 1977; 252:7184-91.

41. Gout PW, Kang YJ, Buckley DJ, Bruchovsky N, Buckley AR. Increased cystine uptake capability associated with malignant progression of $\mathrm{Nb} 2$ lymphoma cells. Leukemia. 1997;11: 1329-37.

42. Wakamatsu K, Ito S, Rees JL. The usefulness of 4-amino-3hydroxyphenylalanine as a specific marker of pheomelanin. Pigment Cell Res. 2002;15:225-32.

43. Zhang H, Bajraszewski N, Wu E, Wang H, Moseman AP, Dabora $\mathrm{SL}$, et al. PDGFRs are critical for PI3K/Akt activation and negatively regulated by mTOR. J Clin Invest. 2007;117:730-8.

44. Hu Z, Wang Y, Huang F, Chen R, Li C, Wang F, et al. Brain expressed $\mathrm{X}$-linked 2 is pivotal for hyperactive mTOR-mediated tumorigenesis. J Biol Chem. 2015;290:25756-65.

45. El-Hashemite N, Zhang H, Walker V, Hoffmeister KM, Kwiatkowski DJ. Perturbed IFN-gamma-Jak-signal transducers and activators of transcription signaling in tuberous sclerosis mouse models: synergistic effects of rapamycin-IFN-gamma treatment. Cancer Res. 2004;64:3436-43.
46. Chen R, Duan J, Li L, Ma Q, Sun Q, Ma J, et al. mTOR promotes pituitary tumor development through activation of PTTG1. Oncogene. 2017;36:979-88.

47. Ito S, Wakamatsu K. An improved modification of permanganate oxidation of eumelanin that gives a constant yield of pyrrole2,3,5-tricarboxylic acid. Pigment Cell Res. 1994;7:141-4.

48. Thody AJ, Higgins EM, Wakamatsu K, Ito S, Burchill SA, Marks JM. Pheomelanin as well as eumelanin is present in human epidermis. J Invest Dermatol. 1991;97:340-4.

49. Loewith R, Jacinto E, Wullschleger S, Lorberg A, Crespo JL, Bonenfant $\mathrm{D}$, et al. Two TOR complexes, only one of which is rapamycin sensitive, have distinct roles in cell growth control. Mol Cell. 2002;10:457-68.

50. Jiang L, Kon N, Li T, Wang SJ, Su T, Hibshoosh H, et al. Ferroptosis as a p53-mediated activity during tumour suppression. Nature. 2015;520:57-62.

51. Kim YC, Guan KL. mTOR: a pharmacologic target for autophagy regulation. J Clin Invest. 2015;125:25-32.

52. Lyons SA, Chung WJ, Weaver AK, Ogunrinu T, Sontheimer H. Autocrine glutamate signaling promotes glioma cell invasion. Cancer Res. 2007;67:9463-71.

53. Lo M, Ling V, Wang YZ, Gout PW. The xc-cystine/glutamate antiporter: a mediator of pancreatic cancer growth with a role in drug resistance. Br J Cancer. 2008;99:464-72.

54. Rosado JO, Salvador M, Bonatto D. Importance of the transsulfuration pathway in cancer prevention and promotion. Mol Cell Biochem. 2007;301:1-12.

55. Uren JR, Lazarus H. L-cyst(e)ine requirements of malignant cells and progress toward depletion therapy. Cancer Treat Rep. 1979;63:1073-9.

56. Gout PW, Buckley AR, Simms CR, Bruchovsky N. Sulfasalazine, a potent suppressor of lymphoma growth by inhibition of the $\mathrm{x}(\mathrm{c})-$ cystine transporter: a new action for an old drug. Leukemia. 2001;15:1633-40.

57. Timmerman LA, Holton T, Yuneva M, Louie RJ, Padro M, Daemen A, et al. Glutamine sensitivity analysis identifies the xCT antiporter as a common triple-negative breast tumor therapeutic target. Cancer Cell. 2013;24:450-65.

58. Cao J, Tyburczy ME, Moss J, Darling TN, Widlund HR, Kwiatkowski DJ. Tuberous sclerosis complex inactivation disrupts melanogenesis via mTORC1 activation. J Clin Invest. 2017;127:349-64.

59. Wataya-Kaneda M, Tanaka M, Yang L, Yang F, Tsuruta D, Nakamura A, et al. Clinical and histologic analysis of the efficacy of topical rapamycin therapy against hypomelanotic macules in tuberous sclerosis complex. JAMA Dermatol. 2015;151:722-30.

60. Yang F, Yang L, Wataya-Kaneda M, Yoshimura T, Tanemura A, Katayama I. Uncoupling of ER/mitochondrial oxidative stress in mTORC1 hyperactivation-associated skin hypopigmentation. J Invest Dermatol. 2018;138:669-78.

61. Prota G. Progress in the chemistry of melanins and related metabolites. Med Res Rev. 1988;8:525-56.

62. Jara JR, Aroca P, Solano F, Martinez JH, Lozano JA. The role of sulfhydryl compounds in mammalian melanogenesis: the effect of cysteine and glutathione upon tyrosinase and the intermediates of the pathway. Biochim Biophys Acta. 1988;967:296-303. 